\title{
Berufshaftpflichtversicherung
}

Im Auftrag der Ärzteschaft überwachen wir laufend den Versicherungsmarkt und handeln für Sie geeignete Lösungen mit Sonderkonditionen aus. So auch bei der Berufshaftpflichtversicherung. Verfügen Sie bereits über eine Nachrisikodeckung von 10 Jahren oder über eine Versicherungssumme, welche, wenn es hart auf hart kommt, auch zweimal innerhalb eines Jahres ausgerichtet werden kann? Überzeugen Sie sich von unserem Angebot und bestellen Sie eine unverbindliche Vergleichsofferte mit dem untenstehenden Talon.

Ich möchte eine kostenlose und unverbindliche Offerte der FMH Insurance Services Berufshaftpflichtversicherung. (Bitte Kopie der aktuellen Versicherungspolice beilegen.)

Fachrichtung

Beschäftigungsgrad

Spezialitäten

Sofern Sie medizinisches Fachpersonal (ohne MPAs und Lehrlinge) angestellt haben:

Anzahl Personen

Beschäftigungsgrad pro Person

Fachrichtung pro Person

$\square \quad$ Bitte senden Sie mir die kostenlose Broschüre «Wichtige Aspekte der Arzthaftung» zu.

$\square \quad$ Ich wünsche eine persönliche Beratung. Bitte rufen Sie mich an.

Vorname / Name

Adresse

PLZ / Ort

Telefon Privat / Geschäft

Beste Zeit für einen Anruf

E-Mail-Adresse

\section{GMH INSURANCE}

Roth Gygax \& Partner AG $\square$ Koordinationsstelle Moosstrasse 2 a 3073 Gümligen

Telefon 0319595000 Fax 0319595010 mail@fmhinsurance.ch www.fmhinsurance.ch

Antworttalon: Bitte einsenden oder per Fax an 0319595010 